\title{
Smart Protection System For Public
}

\author{
Amira Abdullah Nasser Al-Jaafariya, Sumaiyh Mohammed Bani Oraba, and Ramesh Palanisamy
}

\begin{abstract}
Today in the current global scenario, the prime question in every girl's mind, considering the ever-rising increase of issues on people harassment in the recent past is mostly about her safety and security. This paper suggests a new perspective to use technology for people's safety. We propose an idea, which changes the way everyone thinks about people's safety. A day when media broadcasts more of people's achievements rather than harassment, it's a feat achieved! Since we (humans) can't respond aptly in critical situations, the need for a device that automatically senses and rescues the victim is the venture of our idea in this paper. We propose to have a device, which is the integration of multiple devices, hardware comprises of a wearable "Smart band" which continuously communicates with a Smartphone that has access to the internet. The application is programmed and loaded with all the required data, which includes Human behavior and reactions to different situations like anger, fear, and anxiety. With the help of all electronics devices store the information to the controller which can operate the system automatically with intelligence.
\end{abstract}

\section{Index Terms-Smart Protection, Safety.}

\section{BACKGROUND OF THE RESEARCH}

Our project an alternative method is designed for people security that serves as a better alternative to the rest of the available security methods. This project mainly focuses on self-defense on people. Here the system is designed around Arduino micro-controller that uses GPS, GSM, and switch, shockwave generation circuit for self-defense and mems sensor for better security. The basic approach (single click) is to intimidate the instant location and a distress message to cops and the preset number, so that unfortunate incident can be averted and to provide real-time evidence for the action against the perpetrators of crime against people.

\section{A. Scope and Limitation of the Research}

It can be for all people who have a problem or risk, so they can easy to find it supported by the location. also, it's very important for weak people like a woman.

\section{B. Significance of the Research}

It helps people to protect themselves to reduce the risk that faces them. In addition, it is so fast to solve the problem and easy to find the risk.

User and Beneficiary of the Research:

- Reduce the risk, Protect the people

- Fast to face the risk or problem

\section{Existing System AND Proposed System}

In the existing system, there is no safety measure for

Published on November 21, 2019 people not only in day time but also in the night time. In earlier days people safety is not a concerned matter. Tracking of people/child is difficult Drawbacks of the existing system:

There is no device which helps people at emergency situation automatically.

There is no system to take immediate action for people's safety automatically. Here in the proposed system all the operations are controlled and monitored using IoT.

\section{Proposed SySTEM}

In the proposed system we can continuously monitor the People/Child with a wearable safety system, with location update.

\section{A. Advantages of the proposed system}

Tracking of People / Childs is possible with automatic alarm and messaging. The developer gives all the operation done by the system is automatically instruction

\section{BLOCK DIAGRAM}



\section{A. Monitoring Section}

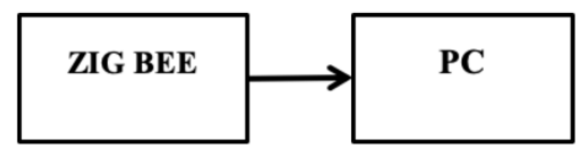

\section{HARDWARE REQUiREMENTS}

a) Arduino Mega

b) Gps 

c) Lcd Display
d) Gsm
e) Iot Module
f) Zigbee (2)
g) Neuro Stimulator
h) Sos Button(2)
i) Buzzer
j) Heart Beat Sensor

\section{A. Software Requirements}
a) Arduino Ide
b) Embedded C

\section{B. Application}

Tracking of People / Childs is possible with automatic alarm and messaging.
a) Parents Can Monitor Their Children's Continuously.

b) People Safety Is Ensured In This Method.

\section{WORKING PRINCIPLE}

In this system, we use ARDUINO MEGA (ATmega2560) microcontroller which acts as the brain of the system, because of the entire system program instruction stored in it.

Here we have a heartbeat sensor to know the abnormal condition of people even people can manually trigger the device to notice others that she is in an emergency situation. The GPS module which we use here to know the exact location of the person, therefore, the location sent to the respective person and also public service organization to take immediate action against people attacks using RF-based wireless module call ZIG BEE. The GSM can send a message or call to the desired person whom the people want to. The system has a neurostimulator for people at the time of emergency to attack back all though we have also used an alarm device to let another know about the emergency situation. All the data are fetched with the help of sensors updated to the cloud. The operation of the system is either controlled or monitored by IoT.

\section{METHODOLOGY}

When the pushbutton is pressed, the GPS transceiver/modem communicates together with the satellites yet then finds bead then longitude information using the triangulation method. Then the GPS modem communicates with the microcontroller yet shops the information touching vicinity into small-sized attention about the UART microcontroller. The GSM module is interfaced along microcontroller in imitation of ship and obtain messages. The reception bolt over the microcontroller is linked according to the transmitting pin over the GSM module, the transmitting nail on the microcontroller is related along the receiving pin of The microcontroller has been coded along programs in imitation of encode the location data as like a Google chart URL which is a quick message to stand despatched according to the helper's mobile. In coding, some AT instructions are old in conformity with ship quick messages. The UART sends the AT CMGS AT instruct in accordance with the GSM module along including the recipient's wide variety and short story as is the google map URL.

\section{CONCLUSION}

This method is very helpful when people does not have any communication method. It is a lesser and moveable system and it cannot be recognized easily as a communication scheme that is, only the user has the familiarity about the system, somebody will not be responsive to it as a security system. It can be simply right within reduced gadgets. It can pathway the person even if they are in a minus coverage area. So this method can be supported anywhere simply and used at any time without much customer communication and with the greatest functionality.

\section{REFERENCES}

[1] Abhijeet Tekawade, Ahmed Tutake, Ravindra Shinde, Pranay Dhole, "Mobile Tracking Application for Locating Friends Using LBS", International journal Innovative research in computer and communication engineering, vol: 1, Issue: 2, April 2013.

[2] Dr.Shantanu K.Dixi, Ashmini, "A Review on Design of GPS and GSM Based Intelligence Ambulance Monitoring”, Journel of engineering and research applications, vol: 4, Issue: 7,July 2014, pp.101-103.

[3] Fuhrmann, W.F, Brass, V. "Performance aspects of GSM radio subsystem", proceeding of the IEEE, vol: 82, issue: 9, Aug 2002.

[4] Abid khan, Ravi Mishra, "GPS-GSM Based tracking system", International Journal of Engineering Trends and Technology, vol: 3 Issue: 2-2012.

[5] V.Jeyasri Arokiamary, "Mobile and Pervasive Computing", Technical Publications, June 2015, pp.26-37. SeokJu Lee,Tewolde,Jaerock Kwon, "Design and Implementation of Vehicle Tracking System using GPS/GSM/GPRS Technology and Smart Phone Application", IEEE, March 2014. [10].Jean J.Labrosse, "Embedded System Building Blocks", CMP Books, January 1999.

[6] https://pandorafms.com/blog/why-you-need-a-monitoring-system/

[7] https://www.javatpoint.com/iot-advantage-and-disadvantage

[8] L. D. X. Shancang Li and S. Zhao, "The internet of things: a survey," Information Systems Frontiers, vol. 17, pp. 243-259, 2015.

[9] F. K. Gerd Kortuem, Dan Fitton and V. Sundramoorthy. (2010) Smart objects as building blocks for the internet of things.

[10] J.-P. Vasseur and A. Dunkels, Interconnecting Smart Objects with IP -The Next Internet, 2010.

[11] A. I. Luigi Atzori and G. Morabito, "The internet of things: A survey," Computer Networks, vol. 54, no. 15, pp. 2787-2805, 2010.

[12] L. P. Luca Mainetti and A. Vilei, "Evolution of wireless sensor networks towards the internet of things: a survey," in Proc. Software, Telecommunications and Computer Networks (SoftCOM), 2011, Dubrovnik, Croatia,2011, pp. 1-6.

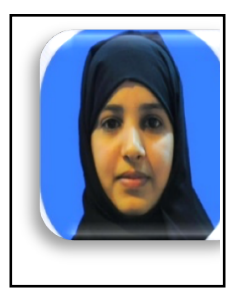

Amira Abdullah Nasser Al-Jaafariya Amira Abdullah Nasser Al-Jaafariya studding B.Tech in networking specialization at ibra college of technology, ibra-Oman.36s1568@ict.edu.om. 
Sumaiyh Mohammed Bani Oraba studying B.Tech in networking specialization at ibra college of technology, ibra-Oman.36s1565@ict.edu.om.

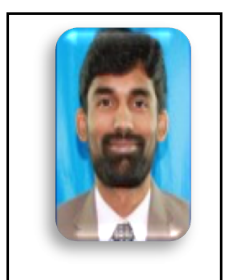

Ramesh Palanisamy obtained his Bachelor's in Barathiar University Coimbatore, India. Then he obtained his Master's degree in Computer Communications, from Barathiar University Coimbatore, India. Currently doing Ph.D. in Computer Science and Engineering (pursuing).Technical Qualifications CCNA, NSP-

(Network Support Professional).HNA-(Hardware Networking Administrator).CCSI - (Cisco Certified System Instructor).He published 18 international journals and 5 conferences .Currently working as lecturer in information technology at Ibra college of technology. rameshphd26@gmail.com. 